\title{
THE
}

\section{Teaching Technology to Older Adults: Modalities Used by Student Mentors and Reasons for Continued Program Participation}

Dara L. LoBuono

Skye N. Leedahl

University of Rhode Island, skyeleedahl@uri.edu

Elycia Maiocco

Follow this and additional works at: https://digitalcommons.uri.edu/hdf_facpubs

The University of Rhode Island Faculty have made this article openly available.

Please let us know how Open Access to this research benefits you.

This is a pre-publication author manuscript of the final, published article.

Terms of Use

This article is made available under the terms and conditions applicable towards Open Access Policy Articles, as set forth in our Terms of Use.

\section{Citation/Publisher Attribution}

LoBouono, D. L., Leedahl, S. N., \& Maiocco, E. (2020). Teaching Technology to Older Adults: Modalities Used by Student Mentors and Reasons for Continued Program Participation. Journal of Gerontological Nursing, 46(1), 14-20. doi: 10.3928/00989134-20191118-02

Available at: https://doi.org/10.3928/00989134-20191118-02

This Article is brought to you for free and open access by the Human Development and Family Science at DigitalCommons@URI. It has been accepted for inclusion in Human Development and Family Science Faculty Publications by an authorized administrator of DigitalCommons@URI. For more information, please contact digitalcommons-group@uri.edu. 
Teaching Technology to Older Adults: Modalities Used by Student Mentors and Reasons for Continued Program Participation

Dara L. LoBuono ${ }^{1}$, Skye N. Leedahl ${ }^{2}$, Elycia Maiocco ${ }^{3}$

University of Rhode Island: ${ }^{1}$ Department of Nutrition and Food Sciences, ${ }^{2}$ Department of Human Development and Family Studies, ${ }^{3}$ Health Studies Program 


\begin{abstract}
This study examined teaching modalities used by college students participating in an intergenerational, service-learning program that helps older adults learn technology and described reasons for older adults' continued participation in this program. Qualitative data analysis was completed using student-maintained observation logs from approximately 200 older participants. We identified eight different teaching modalities used by student mentors, including observing and listening, writing down information or creating visual aids, explaining the significance and simplifying materials, using repetition/review, and utilizing hands-on learning. Six reasons for older adults continued participation were identified: continued progress on one topic or device, multiple topics for advanced use, learning multiple modalities to get connected, and continued learning through take-a-ways, practice and homework. Service-learning programs can help educate health and human service professionals on best practices for working with older adults
\end{abstract}


While technology is becoming embedded in society, older adults are adapting to technology at a slower rate (Pew Research Center, 2017). For instance, while 90\% of all adult Americans have used the internet, only $67 \%$ of older adults report having used the internet. Lack of digital adoption, known as the digital divide (Van Dijk, 2006), can create disparity for older adults. Low levels of digital literacy, agerelated cognitive and physical decline, and negative attitudes can influence technology adoption among older adults (Czaja et al., 2006; Laguna \& Babcock, 1997; Yagil, Cohen, \& Beer 2013). To help increase digital competence among older adults, technology training programs have emerged across the country (Delello \& McWhorter, 2017; Gardner, 2010; Leedahl et al., 2018). However, more information is needed to understand best practices for teaching older adults how to use technology and understand older adults' reasons for continued participation in an intergenerational program.

\section{Digital Competence Among Older Adults}

Older adults can benefit from technology use through increasing access to health information, promoting social connectedness, improving quality of life, preventing cognitive decline, and maintaining independence (Czaja et al. 2006; Tun \& Lachman, 2010). Training older adults to increase digital competence can help them recognize added benefits from using technology and change behavior and attitudes toward technology (Hill, Betts, \& Gardner, 2015). Digital competence is one's confidence and ability to use technologies for communication, information and problem-solving in various aspects of life (Olofsson \& Lindberg, 2008). Older adults' initial technology experiences and how they are taught to use technology can greatly influence ongoing technology adoption (Peek, Wouters, Luijkx, \&Vrijhoef, 2016).

\section{Best Practices for Teaching Older Adults}

A positive initial experience combined with interactive teaching modalities can help promote continual use of technology among older adults in this population (Rogers, Campbell, \& Pak, 2000). Further, programs should create a friendly and supportive environment (Gagliardi, Mazzarini, Papa, Giuli, \& Marcellini, 2008; Hickman, Rogers, \& Fisk, 2007) that covers topics relevant to older adults (Sergist, 2004). Best practices also suggest, providing one-on-one training for older adults with step by step, direct instructions (Duaz, Moore, Smith, Puno, \& Schaag, 2004; Leedahl et al., 2018). Repetition is also an 
important aspect of technology training, as older adults generally need more time to learn new tasks (Delollo \& McWorter, 2017; Tsai, Shillair, \& Cotten 2017). Programs should also provide written materials (Gardener, 2010), and find a balance of self-directed versus instructor directed learning (Dickinson, Eisma, Gregor, Syme, \& Milne, 2005; Xie \& Bugg 2009). Tsai and colleagues (2017) found most older adults learn how to use tablet devices through exploratory, self-directed learning using a "trial and error" or "playing around" approach.

Reverse mentoring, where younger adults provide support and knowledge to older adults, can be a vehicle to teach older adults about technology and bring generations together (Meister \& Willyerd, 2010; Murphy, 2012; Leedahl et al., 2018). Service-learning is an organized community service activity to promote experiential education for students in higher education, while they also earn course credit (Underwood \& Dorfman, 2008). A reverse mentoring, service-learning program can create a mutualistic, open relationship where mentors and mentees share knowledge and experiences (Speitzer, 2006).

However, few studies have examined this model to educate older adults about technology in an interdisciplinary manner at the collegiate level utilizing students preparing to be health and human service professionals as mentors.

\section{Theoretical Framework}

This program uses key principles from Knowles' theory of andragogy (Knowles, 1984), which has been used previously to teach older adults how to use technology (Fink \& Beck, 2015). The theory of andragogy is a constructivist approach to learning, grounded on the notion that adults draw from their own knowledge and experiences to learn and that adults' readiness to learn is strongly related to the relevance of the subject manner to their own lives (TEAL Center Staff, 2011).

\section{Research Design and Methods}

The University of Rhode Island's (URI) Engaging Generations: Cyber-Seniors (E-GEN) is a reverse-mentoring, service-earning program where URI students help older adults learn about technology. Using an interdisciplinary approach, the program includes students and faculty from the Colleges of Pharmacy, Health Sciences, and Arts \& Sciences. Following sessions with older participants, student 
mentors keep an in-depth observation log describing who they worked with, the device and technology topic covered, teaching methods used, and connections made with the older adult beyond technology (Leedah et al.,2018 and LoBuono et al., 2019). As described in student observation log entries, the majority of sessions were individual, where one older adult worked with one student. Eighteen observation log entries described sessions where one older adult worked with two students during a session s and nine entries described group sessions consisting of two to seven older adults and one to three mentors.

The purpose of this paper is to describe the modalities used by college students to teach older adults about technology and older adults' reasons for continued participation in an intergenerational service-learning program. These research purposes were addressed by completing qualitative analysis of the student observation logs. This research project was approved by the university Institutional Review Board and included data collected from the 2016-2017 academic year. During this time, roughly 27 student mentors and 199 older adults ages 50-88 participated in the program.

\section{Qualitative Analysis}

Qualitative data were analyzed using a narrative research approach. Narrative research, through storytelling, seeks to understand meanings participants give themselves, their environment, and their lived experience (Josselson, 2011). To examine the first aim, 109 pages of student-maintained observation logs from 27 students and 199 older adults were analyzed. To examine the second aim, which emerged from the data while examining the first aim, we analyzed a subset of observation-logs from 30 participants who met with a student mentor three or more times (50 pages of observation logs).

The primary researcher (DL) went through the observation logs to identify initial codes and discussed these codes with the faculty researcher (SL). DL and SL collapsed overlapping themes, added additional codes, and reached agreement on initial codes. After this, DL and a research assistant (EM) coded the first four pages of the observation logs separately. The two researchers came together to compare codes, and an agreement of greater than $80 \%$ was achieved; disagreements were discussed and rectified. The observation logs were then uploaded into NVivo 11. The primary researcher and the 
research assistant separately coded the entire document in NVivo using identified themes. An inter-coder reliability was found acceptable for both aims (Bazeley \& Jackson, 2013; Saladaña, 2016). For Aim 1, $80.02 \%$ agreement was found and a kappa coefficient $(\mathrm{k})$ of 0.54 . For Aim 2, 99.75\% agreement was found, with a $\mathrm{k}$ of 0.58 . The primary researcher and research assistant met to discuss differences in coding and reached an agreement. Finally, DL and SL collapsed and finalized themes together.

\section{Teaching Modalities}

\section{Results}

Teaching modality themes used by student mentors and supporting quotes are highlighted in Table 1. Themes are listed based on number of times mentioned from most to least.

Observing and Listening to Mentors. The observational learning method was used to describe when student mentors completed the activity, and the participant watched and listened as the mentor went through the task. The method was often used to teach basic functions of technology, such as helping participants charge devices, connect to $\mathrm{Wi}-\mathrm{Fi}$, search the web, and get organized. Observing was also used when older adults wanted clarification about certain topics to utilize technology more, such as the meaning of emojis, de-friending versus unfollowing friends on social media, and downloading versus uploading documents.

Providing Step by Step Instruction. Mentors slowly provided clear, concise verbal or written instructions in a step by step manner. This allowed the participants to practice and use technology on their own. Mentors who wrote down instructions helped participants learn how to: connect to the Wi-Fi, access Facebook, download music, and make slideshows with photos. Mentors often wrote down passwords or encouraged participants to write down passwords, since many struggled with remembering passwords. Many older adults also wrote down instructions as mentors taught them aspects of technology. Using written instruction also frequently overlapped with using visual aids. Visual aids helped older adults during sessions to make sense of their questions, such as watching a demonstration video, downloading screenshots of directions, or drawing symbols. Mentors also empowered participants to search for instructions on their own. 
Explaining the Significance and Simplifying Materials. For most participants, mentors reviewed different applications/programs and explained their use; this allowed participants to decide whether or not these programs would be useful for them. In order to explain various aspects of technology, mentors simplified information and used metaphors and analogies to make the information more relatable to participants. Sessions not only taught older adults how to use technology, but helped them better understand certain aspects of it and provide context to help them increase their digital competence. Understanding the meanings and purpose of different program symbols helped older adults get more comfortable with technology and different programs and applications, which allowed older adults to figure out what they could use technology for and minimize apprehension.

Using Repetition and Review. During sessions, mentors often went over topics multiple times.

This indicates older adults need to learn information more than once to increase their digital competence, minimize confusion, and feel comfortable using technology independently. This has been referred to as the "drill and practice" teaching method (i.e., a form of independent study where after the teacher explains the task, the learner practices it) (Petrina 1999). Some mentors would review the content during the session until participants demonstrated they could complete a task on their own. Older adults who did not review or practice in between sessions often needed mentors to reteach and review information.

Utilizing Hands-On Learning. Sessions where mentors had older adults practice tasks on their own were coded as hands-on training. Mentors also used the teach-back method, where they would demonstrate to the older adult how a task is completed, and then have the older adult complete the task on their own and explain it to the mentor. The teach-back method enriched sessions and communication with participants. Using hands-on learning allowed a greater dialogue between the mentor and participant and enabled the mentor to not only understand what the older adult wanted to learn, it also allowed the participant to teach the mentor something new related to technology.

Collaborative Learning. Collaborative learning, when mentor and mentee work together, was coded when mentors worked with the older adult to figure out how to use a certain aspect of a device or program. In collaborative learning, the mentor and mentee shared their knowledge and expertise to foster 
a mutually integral relationship. In fact, mentors often brainstormed ideas with their mentee. For instance, one older adult wanted to promote her business online and had an idea of what she wanted to do but needed the technology expertise of the mentor to do so.

Practicing Through Trial and Error. The trial and error method or "playing around" is an exploratory and self-directed learning style (Tsai et al., 2017; Schunk, 1989). This strategy was used by mentors if they were unfamiliar with a technology-related task that older adults were interested in, and also seemed to work well during small group sessions.

Using Multiple Teaching Modalities. Entries from many observation logs utilized multiple teaching modalities to meet participants' needs. Students' use of multiple teaching modalities demonstrates their ability to provide individualized instructions (i.e., where teaching and learning is customized to meet a learner's unique characteristics) (Petrina, 1999). Mentors often combined the step by step method with other teaching modalities. The strategy was successful for a pharmacy student who met with three different clients about topics such as texting, searching the web, twitter, online shopping, resumes, and downloading a coupon app. Repetition was often paired with other teaching modalities, such as the step by step method.

\section{Reasons for Continued Participation}

We examined reasons for continued participation among 30 older adults who attended three or more cyber senior sessions. The number of sessions attended ranged from 3-13. The five emerging themes and supporting quotes are highlighted in Table 2. By extending beyond teaching modalities used within sessions, we were able to explore how older adults' digital competence evolved and understand which topics were covered over multiple sessions. Most older adults who attended multiple sessions were able to become experts in a topic or device.

Continued Progress on One Topic or Device. Participants sometimes spent multiple sessions working to master a device (e.g., smart phones, tablets, e-readers) or a specific program or technologyrelated (e.g., photo management, email, Facebook, Craigslist). For example, one participant in her sixties spent five sessions learning how to use her Nook. Another participant around the age of 80 attended eight 
sessions to learn how to use an iPad. Another participant in her late sixties worked with a mentor over three sessions to learn Facebook (e.g., unfollowing people, messenger, sharing photos and links, and the difference between a comment and a personal message). Finally, one participant with memory loss, age 70, learned about Craigslist for buying and selling items over 13 sessions. The mentor used repetition, hands-on learning, and written instruction to assist him, which highlights the importance of repetition and multiple modalities particularly when older adults have short-term memory loss. It also shows mentors that older adults with cognitive impairments can learn new skills but must learn at a slower pace and see the information multiple times.

Multiple Topics Over Time for Advanced Use. Older adults attending multiple sessions inquired about a variety of topics, ranging from basic functions of technology, communication, organization, leisure activities, and productivity. Over five sessions, a seventy-year-old participant learned to reset passwords, use email, online shop, and search the web. Another participant in her sixties attended four sessions to go over features of her Apple devices. Findings show that multiple sessions to teach older adults can help them understand the different uses and benefits of technology and help older adults utilize technology for a variety of purposes.

Continued Learning Through Take-a-ways, Practice and Homework. Older adults benefited from practicing technology at home when provided with materials and directions to guide them through homework. Practice during sessions and in between sessions aided older adults in increasing their digital competence. Providing written materials was well-received by participants and was particularly helpful for those participants who attended multiple sessions. Those who did not spend time using technology in between sessions did not appear to increase their digital competence as much as those who practiced on their own.

Learning Multiple Modalities to Get Connected. Older adults were interested in using technology to stay connected with others and maintain relationships. Some older adults who attended multiple cyber senior sessions used the sessions to learn about the different modalities to get connected, including texting, email, videoconference, and social media. Depending on their level of competence, some older 
adults focused on multiple communication mediums, while others started with mastering one or two. Increased competence in using multiple digital communication platforms can promote social and civic participation and maintain relationships.

Increased Confidence Over Time. Older adults who attended multiple sessions, practiced their information, and/or utilized written materials to enhance learning, exhibited an increased confidence in their ability to use technology. The ability for older adults to feel comfortable with younger mentors and ask questions helped to enhance learning and helped college students better understand ways to individualize sessions tailored toward their participants' needs. Mentors also recognized that confidence and comfort with technology emerged at different rates. Older adults' increased confidence minimized frustrations, created positive attitudes toward technology, and increased technology adoption. The opportunity to learn new tasks, such as how to use technology, may also help promote older adults' overall well-being.

\section{Discussion}

This study examined teaching modalities used by college students participating in a servicelearning, reverse-mentoring program and reasons for older adults' continued participation. We found college students used multiple teaching modalities and tailored sessions to meet older adults' learning styles and preferences. Additionally, those older adults who attended three or more sessions were able to enhance their digital competence skills in one or more areas of technology while learning at their own pace. Nursing and other programs educating the future health and human service workforce could consider implementing programs like this to both expose younger students to older individuals and prepare students to be mentors.

\section{Best Practices for Teaching Older Adults}

Student mentors used multiple modalities to tailor sessions for each participant, which is supported by the existing literature (Duaz et al., 2004; Vroman, Arthanat, \& Lysack, 2015). Many of the approaches used by students followed best practices proposed by Jones and Bayen (1998) including: breaking up instructions into smaller units with a specific goal; relating new information to older adults' 
existing knowledge; using hands-on activities and allowing older adults to practice; working on one task at a time; allowing time for older adults to take notes and have time to ask questions; using explicit language to avoid confusions and inferences; and connecting older adults with online help resources that accompany programs. The majority of sessions were one-on-one, and mentors provided step by step verbal and/or written instructions, where students reported using clear and concise language (Duaz, et al., 2004; Gatto \& Tuk, 2008). Students also frequently used analogies or related technology topics to help older adults understand how to use technology. Although our mentors documented using a variety of teaching modalities, the majority relied heavily on observational learning, a method less supported in the literature. Many older adults needed help performing basic functions (LoBuono et a., 2019) which may be why so many mentors used the strategy of observational learning. Further, observational learning may be beneficial in allowing older adults to witness how technology can enrich their lives (Heaggans, 2012). Understanding the benefits of technology and how it can be applied aligns with the adult learning theory (Knowles, 1984).

Additionally, thirty of our participants attended at least three sessions, where the majority made continued progress on one topic or device. Some also learned how to use other programs and software through frequent sessions. Continued practice and additional experience may help decrease cognitive decline and short-term memory barriers, as neural connections in the brain can be made to learn new information, in turn possibly protecting against age-related cognitive decline (Vance et al. 2008). Our findings, in conjunction with previous research, suggest that programs teaching older adults about technology should frequently review a topic multiple times. Programs should also encourage older adults to practice on their own in between sessions.

\section{Implications for Promoting Older Adults' Technology Adoption Over Time}

This study is novel because it examines an intergenerational mentoring program that promotes technology adoption among older adults and allows older adults to influence what information they learn and how they learn; therefore, knowledge is transferred and reinforced. Like other intergenerational programs, our program contributes to the development of community-university partnerships, which in 
turn can promote the well-being and quality of life for the older adult population (Au, Garner, Lai \& Chan, 2015). Specifically, our program shows that one-on-one sessions allow student mentors to tailor teaching strategies to meet older adults' individualized needs and allow sessions to build off one another to promote continued learning around areas of interest. This notion supports recommendations from Heaggans (2012), who champions and promotes the need for older adults to learn technology that meets their daily activities and preferences.

Service-learning programs can help educate health and human service professionals on best practices for working with older adults (Augustin \& Freshman, 2016). Findings from our study provide guidance for students in these types of programs. Specifically, intergenerational service-learning programs can help nursing and other health professional students gain experience with communicating and teaching older adults. The teaching strategies learned could be translated to teaching other topics (e.g., treatment or drug regimens, disease progression) that could be helpful in future careers.

\section{Study Limitations and Future Research}

The present study was limited in the fact that only student perceptions were analyzed. While student-maintained observation logs were detailed in most cases, some student logs were less so and made it difficult to ascertain teaching modalities used. Additionally, how older adults evaluated and perceived the effectiveness of student teaching styles was not investigated. Future research should analyze and compare qualitative and quantitative data capturing both the experience of the older adult and mentor. Finally, findings may not be generalizable to other populations.

\section{Conclusion}

Student mentors used a variety of modalities to teach older adults how to use technology. Nursing programs and other programs working to prepare health and human service professionals could consider introducing reverse mentoring programs and utilize the teaching strategies identified in this article to train and support students in their future work with older adults. 


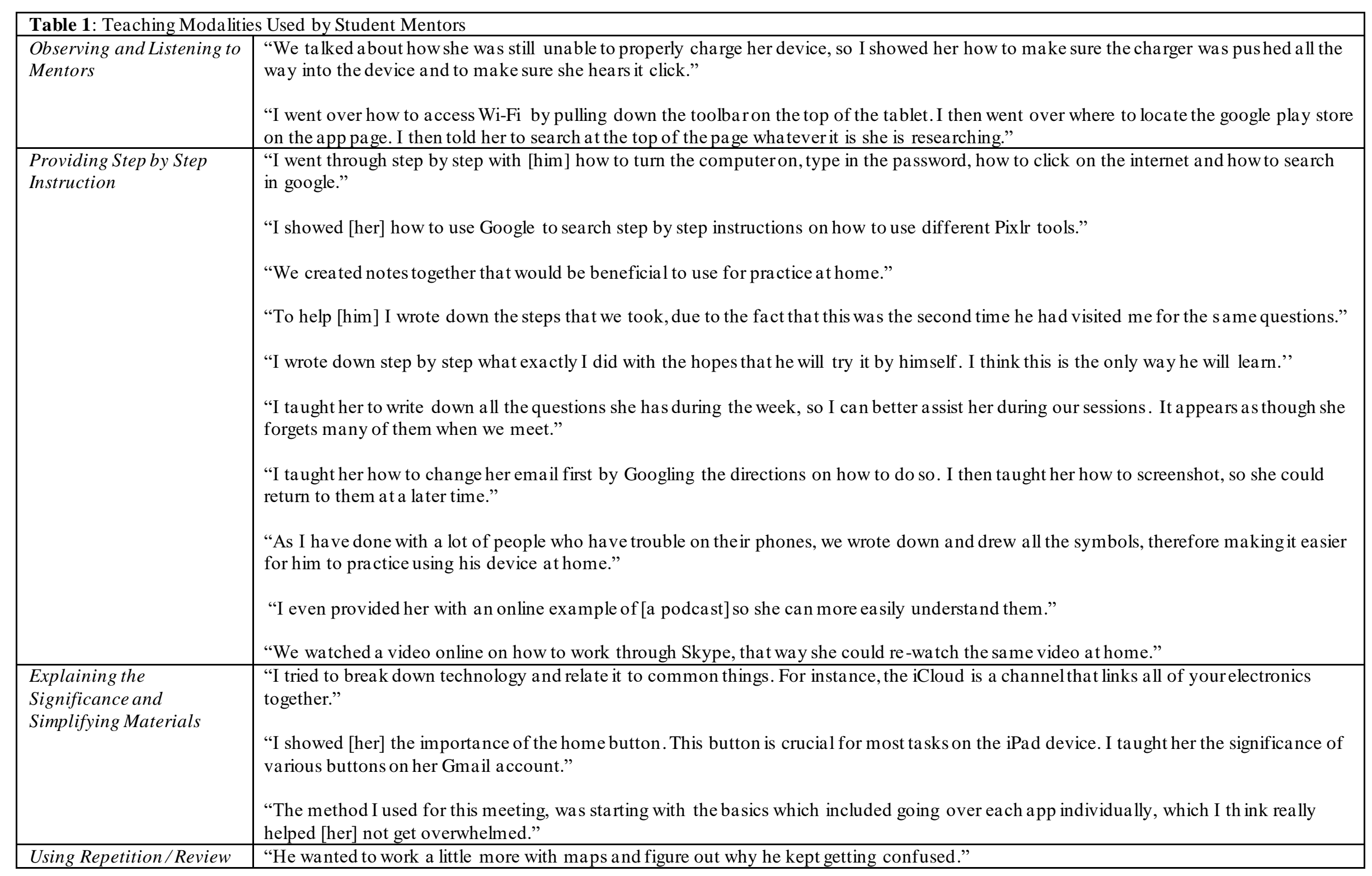




\begin{tabular}{|c|c|}
\hline & $\begin{array}{l}\text { "This was my second session with [her], and she came in proud to show me she remembered what I had taught her previously." } \\
\text { "We continued to work with WiFi and email. For the session we practiced these skills, until she had a good handle on how to use them." } \\
\text { "We continued our work on his phone, but since he had not practiced that much we mostly started from scratch. We talked about the icons } \\
\text { on his phone, and how to use them properly. We also discussed the phone application, and the different ways to call people." } \\
\text { "We worked on online shopping, afterwe reviewed everything, we had done together this semester... We spent about half of ourt ime } \\
\text { working on her tablet, reviewing emails and contacts, then learning how to online shop." }\end{array}$ \\
\hline $\begin{array}{l}\text { Utilizing Hands-On } \\
\text { Learning }\end{array}$ & $\begin{array}{l}\text { "I showed her how to make group emails on her computerand also how to add a signature to all of her emails. I talked her through } \\
\text { everything while she actually did everything on her computer, that way she could learn with me there" } \\
\text { "He learned best by doing everything as I told him the instructions." } \\
\text { "I made sure that my participants were able to do the physical a spects of fixing the problems with their own hands -on the keyboard, while I } \\
\text { instructed them or intervened to demonstrate directly only when necessary." } \\
\text { "When we went through maps, we discussed what all the icons did, and practiced using the app a few times so that way he had a better } \\
\text { understanding. For messaging he seems to have really gotten it, so I didn't need to teach him much! I see [him] about twice a week and we } \\
\text { are quite close." } \\
\text { "[I] showed him how to create new calendarevents, betterunderstand text messaging and the app, and YouTube. Allowed him to control } \\
\text { what we were doing by letting him type and using the teach-back method for newideas. He taught me about Waze and how it is an easy } \\
\text { GPS app forhim to use. We also talked with his wife who also came in with him." }\end{array}$ \\
\hline Collaborative Learning & $\begin{array}{l}\text { "We connected over trying to access her documents togetherconsidering I am not too familiar with the cloud myself." } \\
\text { "Though I am not too familiar with the program [Excel] we were able to work together to answer her questions ...For Excel, she wanted to } \\
\text { learn how to insert the commas in between numbers in the thousands. I taught her to do so by clicking with the mouse exactly where she } \\
\text { would like to put them." } \\
\text { "I taught her how to use the lasso tool on Pixlr and we learned how to blur things together." } \\
\text { "We also worked on her Facebook page, and thought of ideas for getting more attention to her business. The hyperlink button and how to } \\
\text { edit a link in both title and color, was the best tip that I showed during this meeting, because it would be ratheruseful for the rest of her } \\
\text { website. This was the first time that [her] and I had met, but we got along great. We had a lot in common, including our love for yoga and } \\
\text { Buddhist culture. The hour session flew by, and it was fun working with her because it was a different kind of meeting then I am used to." } \\
\text { "[He] showed me how to look at stocks and explained what the numbers meant since I know no thing about the stock market." }\end{array}$ \\
\hline
\end{tabular}




\begin{tabular}{|c|c|}
\hline & $\begin{array}{l}\text { "...Together the three of us went through each ringtone to find the one that best suited [him]. We sat together and laughed about the } \\
\text { ringtones for about } 15 \text { minutes until he decided on one." }\end{array}$ \\
\hline $\begin{array}{l}\text { Practicing Through Trial } \\
\text { and Error }\end{array}$ & $\begin{array}{l}\text { "He was curious about the databases he could access through the public library. He wanted to access obituaries because he liked trying to } \\
\text { link the lives of people together and see their history. I wa s not sure how to help him with this, as it was something I had never done before } \\
\text { so we just went through and tried a trial and error approach and eventually found what he was looking for." } \\
\text { "We went over Craigslist again today. He is concerned as to why people are not contacting him about his products. With that being said, I } \\
\text { suggested that he added photos onto his adds. So, we mainly focused on getting his photos off of his phone and onto the computer. With } \\
\text { some playing around, we were able to figure this out and adding his photos was a success." } \\
\text { "We messed around with the maps application and also added her location to the weather app so she could check the weather in the } \\
\text { morning if she did not feel like watching the news." } \\
\text { "For our first sessions I handed out the iPads and let them do as they plea sed. I walked around and tried to get a general idea of what they } \\
\text { were interested in learning or what they already knew. I helped each attendee with something different and unique and gave them all } \\
\text { pointers that will be brought up aga in in a specific lesson." }\end{array}$ \\
\hline $\begin{array}{l}\text { Using Multiple Teaching } \\
\text { Modalities }\end{array}$ & $\begin{array}{l}\text { "I gave my participants clear and concise instructions and had them write them in case they forgot them.I also had them show me how to } \\
\text { perform a certain task on their own to make sure they understood how to use the device." } \\
\text { "I first showed the ladies how to perform the task, and then asked if they remembered how to do it. They also took notes about what we } \\
\text { ta lked about so that they could remember how to do it la ter." } \\
\text { "[She] came in with her iPad a gain and she wanted to help delete emails in a faster manner and also she needed help with the functioning of } \\
\text { certain apps. I walked through the steps multiple times and then showed her how to select multiple messa ges to delete them." } \\
\text { "We went over how to use Craigslist again. We usually review the same materialevery session. Since I had previously wrote down step by } \\
\text { step how to perform the task he is interested in, I basically sit back and allow him to do it himself. Of course, I offerhim support while } \\
\text { doing so seeing as he is not fully confident in adding photos all by himself." } \\
\text { "I helped him by showing him how to zoom out to get a better view of the slide and picture he was using. I also showed him how to save } \\
\text { and rename his slideshow videos. He wrote down some of the steps I taught him." }\end{array}$ \\
\hline
\end{tabular}

\begin{tabular}{|l|l|}
\hline Table 2: Reasons for Continued Participation \\
\hline $\begin{array}{l}\text { Continued Progress on } \\
\text { One Topic or Device }\end{array}$ & $\begin{array}{l}\text { "This week we continued with ga ining progress on her Nook. We continued to look through the different categories listed on her eBook and } \\
\text { then tackled the different sections she was curious about." } \\
\text { "This week we updated his phone and walked through all the changes that happened. Then we continued to work on messaging and came } \\
\text { up with a ga me plan for our meeting on Wednesday." }\end{array}$ \\
\hline
\end{tabular}




\begin{tabular}{|c|c|}
\hline & $\begin{array}{l}\text { "We ta lked about how she suffered from a stroke 6-7 years ago and she forgot how to use Word and Excel which she previously used in her } \\
\text { job as an accountant." }\end{array}$ \\
\hline $\begin{array}{l}\text { Multiple Topicsfor } \\
\text { Advanced Use }\end{array}$ & $\begin{array}{l}\text { "[She] came into the session saying, "teach me everything."” } \\
\text { "We also searched, 'the benefits of coconut oil' on Google, in which we all learned a lot. We also showed him how to look up videos and } \\
\text { music on YouTube, where we listened to a few songs." } \\
\text { "I helped her with everything that was on her MacBook and showed her what each individual program was and how to use some of them." }\end{array}$ \\
\hline $\begin{array}{l}\text { Continued Learning } \\
\text { through Take-A-ways, } \\
\text { Practice and Homework }\end{array}$ & $\begin{array}{l}\text { "She watched me do everything once and then she would go back and repeated the steps until she could remember." } \\
\text { "He came in with his iPad and wanted to learn how to better utilize reminders, and he also wanted to go over the various ico ns he has found } \\
\text { while looking through various apps. I continued to write down explanations and steps that we followed within the various apps so he could } \\
\text { follow a long on his own at home." } \\
\text { "She had not used [her Amazon Fire Tablet] since our sessions last semester and wanted to freshen up on her knowledge. Together we went } \\
\text { over her Facebook account and downloading the app again because it was not working. After that we discussed all the different apps that } \\
\text { were linked to Amazon, such as the shopping and books app." }\end{array}$ \\
\hline $\begin{array}{l}\text { Learning Multiple } \\
\text { Modalities to Get } \\
\text { Connected }\end{array}$ & "We went over aga in how to maneuver through Facebook and her email." \\
\hline $\begin{array}{l}\text { Increased Confidence Over } \\
\text { Time }\end{array}$ & $\begin{array}{l}\text { "For messaging he seems to have really gotten it, so I didn't need to teach him much! I see [him] about twice a week and we are quite } \\
\text { close." } \\
\text { "I am really proud of his success with his devices, and the improvements he has made. This session we scheduled over time in order to keep } \\
\text { working on these skills. Our relationship has really grown." } \\
\text { "I helped [him] begin to feel more comfortable with his new iPad." After the second session the mentor noted: "Over time he has become } \\
\text { more comfortable chatting with me and a sking questions." } \\
\text { "She is so proud of herself, it was a wesome to see her get so excited about learning and understanding." Previously, during o ne of these } \\
\text { sessions, mentor logged: "[We] joked about how she will be able to email me back in time for my graduation." } \\
\text { "Beyond technology we discussed how this class has made her less a fraid of practicing and trying new things. She explained that now } \\
\text { instead of calling her son for things she needs help with, she will try it first herself if she believes it's something she may be able to handle." }\end{array}$ \\
\hline
\end{tabular}




\section{References:}

Au, A., Ng, E., Garner, B., Lai, S., \& Chan, K. (2015) Proactive aging and intergenerational mentoring program to promote the well-being of older adults: pilot studies. Clinical Gerontologist, 38:203-210.

Augustin, F., \& Freshman, B. (2016). The effects of service-learning on college students' attitudes toward older adults. Gerontology \& Geriatrics Education, 37(2), 123-144. doi:10.1080/02701960.2015.1079705

Bazeley, P., \& Jackson, K. (2013). Qualitative data analy sis with NVivo. (2nd edn). Thousand Oaks, CA: Sage.

Czaja, S.J., Charnesss, N., Fisk, A.D., Hertzog, C., Nair, S.N., Rogers, W.A., \& Sharit, J. (2006).

Factors predicting the use of technology: findings from the center for research and education on aging and technology enhance ment (CREATE). Psychology and Aging, 21, 333-352. DOI:10.1037/0882-7974.21 .2.333

Delello, J. A., \& McWhorter, R. R. (2017). Reducing the digital divide: Connecting older adults to iPad technology. Journal of Applied Gerontology, 36(1), 3-28.doi:10.1177/0733464815589985

Dickinson, A., Eisma, R., Gregor, P., Syme, A., \& Milne, S. (2005). Strategies for teaching older people to use the World Wide Web. Universal Access in the Information Society, 4(1), 3-15.

Duaz, E., Moore, J., Smith, C. E., Puno, F., \& Schaag, H. (2004). Installing computers in older adults' homes and teaching them to access a patient education web site: A systematic approach. Computers, Informatics, Nursing, 22(5), 266-272.

Fink, A., \& Beck, J. C. (2015). Developing and evaluating a website to guide older adults in their health 
information searches: A mixed-methods approach. J Appl Gerontol, 34(5), 633-651. doi:10.1177/0733464813486961

Gardner, P. J. (2010). Older adults and OATS computer training programs: A social impact analysis. Retrieved from

The New York Academy of Medicine. Division of Health Policy. New York, NY

Gagliardi, C., Mazzarini, G., Papa, R., Giuli, C., \& Marcellini, F. (2008). Designing a learning program to link old and disabled people to computers. Educational Gerontology, 34(1), 15.

Gatto, S.L. \& Tak, S.H. (2008). Computer, internet, and e-mail use among older adults: Benefits and barriers.

Educational Gerontology, 34:9, 800-811, DOI: $\underline{\text { 10.1080/03601270802243697 }}$

Heaggans, R.C. (2012). The 60's are the new 20's: Teaching older adults technology. SRATE Journal, 21(2), 1-8.

Hickman, J. M., Rogers, W. A., \& Fisk, A. D. (2007). Training older adults to use new technology. J Gerontol B Psychol Sci Soc Sci, 62 Spec No $1,77-84$.

Hill, R., Betts, L. R., \& Gardner, S. E. (2015). Older adults' experiences and perceptions of digital technology:

(Dis)empowerment, wellbeing, and inclusion. Computers in Human Behavior, 48, 415-423. doi:OI: 10.1016/j.chb.2015.01.062

Jones, B.D. \& Bayen, U.J. (1998). Teaching older adults to use computers: Recommendations based on cognitive aging research.

Educational Gerontology: An International Quarterly, 24:7, 675-689, DOI: 10.1080/0360127980240705

Josselson, R. (2011). Narrative research: Constructing, deconstructing, and reconstructing story.

In F.J. Wertz, K. Charmaz, L.M. McMullen, R. Josselson, R. Anderson, and E. McSpadden (Eds.), Five ways of doing qualitative analysis (pp. 224-242). New York, NY: The Guilford Press.

Knowles, M. and Associates (1984). Andragogy in action: Applying modern principles of adult 
learning. San Francisco: Jossey-Bass.

Laguna, K. \& Babcock, R.L. (1997). Computer anxiety in young and older adults: implications for human-computer interactions in older populations. Computers in Human Behaviors. 13(3), 317-326. https://doi.org/10.1016/S0747-5632(97)00012-5

Leedahl, S. N., Brasher, M. S., Estus, E., Breck, B. M., Dennis, C. B., \& Clark, S. C. (2018). Implementing an interdisciplinary intergenerational program using the Cyber Seniors(R) reverse mentoring model within higher education. Gerontol Geriatr Educ, 1-19. doi:10.1080/02701960.2018.1428574

LoBuono, D.L., Leedahl, S.N., \& Maiocco, E., (In Press, 2019). Qualitative analysis of technology use for older adults in a Cyber-Seniors® Program. Gerontechnology.

Meister, J.C., \& Willyerd, K. (2010). Mentoring millennials. Harvard Business Review, 88(5), 65-72.

Murphy, W. (2012). Reverse mentoring at work: Fostering cross-generational learning and developing millennial leaders. Human Resource Management, 51,549-574.

Olofsson, A. D., \& Linberg, O. J. (2008). An ethical perspective on ICT in the context of the other. In Handbook of Research on Digital Information Technologies: Innovations, Methods, and Ethical Issues (pp. 506-521). Hershey, PA Information Science Reference

Peek, S. T., Wouters, E. J., Luijckx, G. J., \& Vrijhoef, H. J. (2016). What it takes to successfully implement technology for aging in place: Focus groups with stakeholders. J Med Internet Res, 18(5), e98. doi: 10.2196/jmir.5253.

Petrina, S. (1999). Instructional methods and learning Styles. In Curriculum and Instruction for Technology Teachers.

Pew Research Center. (2017). Tech adoption climbs among older adults. Retrieved from 


\section{http://assets.pewresearch.org/wpcontent/uploads/sites/14/2017/05/16170850/PI_2017.05.17_Older-Americans-Tech_FINAL.pdf}

Rogers, W. A., Campbell, R. H., \& Pak, R. (2000). Systems approach for training older adults to use technology. In Communication, technology, and aging: Opportunities and challenges for the future (pp. 187-208): Springer Publishing Company.

Saladaña, J. (2016). The coding manual for qualitative researchers. (3rd edn). Thousand Oaks, CA: Sage.

Schunk DH (1989). Social cognitive theory and self-regulated learning. In B.J. Zimmerman \& D.H Schunk (Eds.), Self-regulated learning and academic achievement (pp.83-110). New York, NY: Springer

Sergist, K. A. (2004). A computer training program for older adults: identifying and overcoming barriers to continued computer usage. Activities, Adaptation \& Aging, 28(4), 13-26. doi: 10.1300/J016v28n04_02

Speitzer, G.M. (2006). Leading to grow and growing to lead: Leadership development lessons from positive organizational studies. Organizational Dynamics, 35, 305-315. https://doi.org/10.1016/j.orgdyn.2006.08.005

Teaching Excellence in Adult Literacy (TEAL) Center Staff. (2011). TEAL center fact sheet no.11: Adult learning theories. Retrieved from: https://lincs.ed.gov/sites/default/files/11_\%20TEAL_Adult_Leaming_Theory.pdf

Tsai, H.S., Shillair, R., \& Cotten, S.R. (2017). Social support and "playing around”: An examination of how older adults acquire digital literacy with tablet computers. Journal of Applied Gerontology, 36(1) 29-55.

Tun, P. A., \& Lachman, M. E. (2010). The association between computer use and cognition across adulthood: Use it so you won't lose it? Psychol Aging, 25(3), 560-568. doi:10.1037/a0019543

Underwood, H. L., \& Dorfman, L. T. (2008). A view from the other side: Elders' reactions to intergenerational service-learning. Journal of Intergenerational Relationships, 4(2), 43-60. doi:10.1300/J194v04n02_04 
Vance, D.E., Webb, N.M., Marceaux, J.C., Viamonte, S.M., Foote, A.W., \& Ball, K.K. (2008). Mental stimulation, neural plasticity, and aging: Directions for nursing research and practice. The Journal of Neuroscience Nursing, 40, 241-249.

van Dijk, J. A. G. M. (2006). Digital divide research, achievements and shortcomings. Poetics, 34(4-5), 221-235.

DOI: 10.1016/j.poetic.2006.05.004

Vroman, K. G., Arthanat, S., \& Lysack, C. (2015). “Who over 65 is online?” Older ad ults' dispositions toward information communication technology. Computers in Human Behavior, 43, 156-166.http://dx.doi.org/10.1016/j.chb.2014.10.018

Xie, B., \& Bugg, J. M. (2009). Public library computer training for older adults to access high-quality Internet health information. Libr Inf Sci Res, 31(3), 155. doi:10.1016/j.lisr.2009.03.004

Yagil, D., Cohen, M., \& Beer, J. D. (2016). Older adults' coping with the stress involved in the use of everyday technologies.

J Appl Gerontol, 35(2), 131-149. doi:10.1177/0733464813515089 